\title{
Rhino-cerebral Mucormycosis: A Ten Year Single Centre Case Series
}

\author{
College of Medicine, University of Basrah, Basrah, Iraq \\ Miss. Sangha Mitra Mummadi, Mr. Husham Barrak, Mr. Adnan Darr
}

\section{Introduction \& Background:}

- Rhino-cerebral mucormycosis (RCM) is a rare opportunistic infection of the paranasal sinuses and brain caused by saprophytic fungi [Figure 1]. The most common causative organism is of the genus Rhizopus [1].

- Patients with impaired immune function due to poorly controlled diabetes mellitus, underling malignancy, neutropenia or use of immunosuppressive agents are considered at high risk of developing RCM.

- RCM may present with unilateral retro-orbital pain, facial pain, numbness, fever, hyposmia or nasal congestion. In patients with central nervous system involvement headaches, reduced consciousness and focal neurological signs may be present [2].

- Vascular invasion and local necrosis are characteristic consequences of the infective process [Figure 2].

- The medical management of RCM involves antifungal therapy and management of underlying predisposing conditions. First line antifungals used in RCM are amphotericin derivatives[3].

- Surgical management involves sinonasal drainage and debridement of involved orbital and cerebral contents. Serial debridement may be required to satisfactorily control disease.

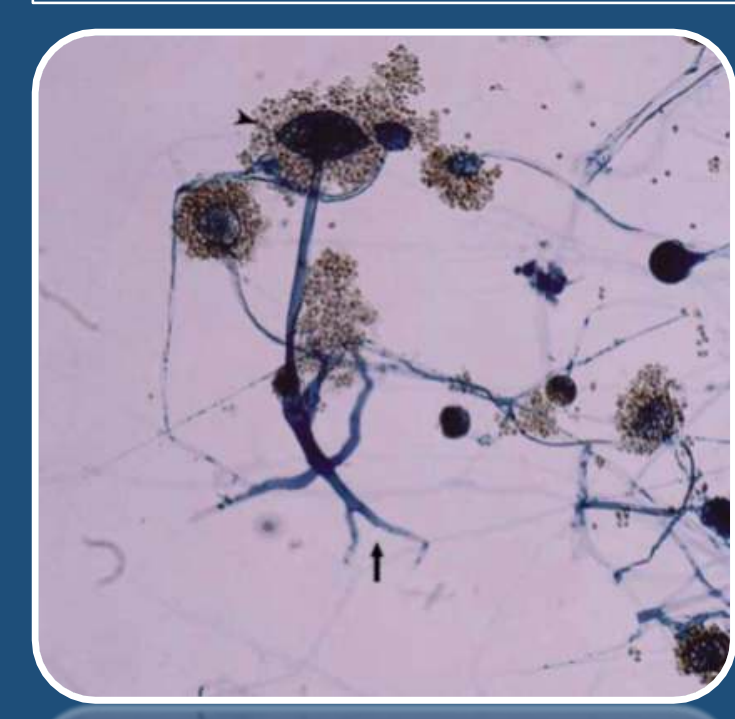

Figure 1: Irregular non-septate hyphae of Rhizopus [4]

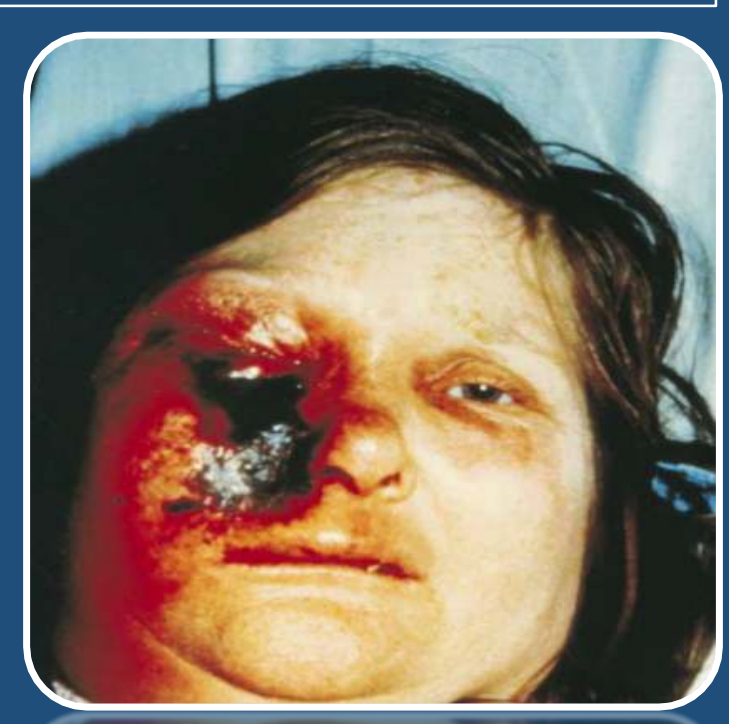

Figure 2: Local necrosis[4]

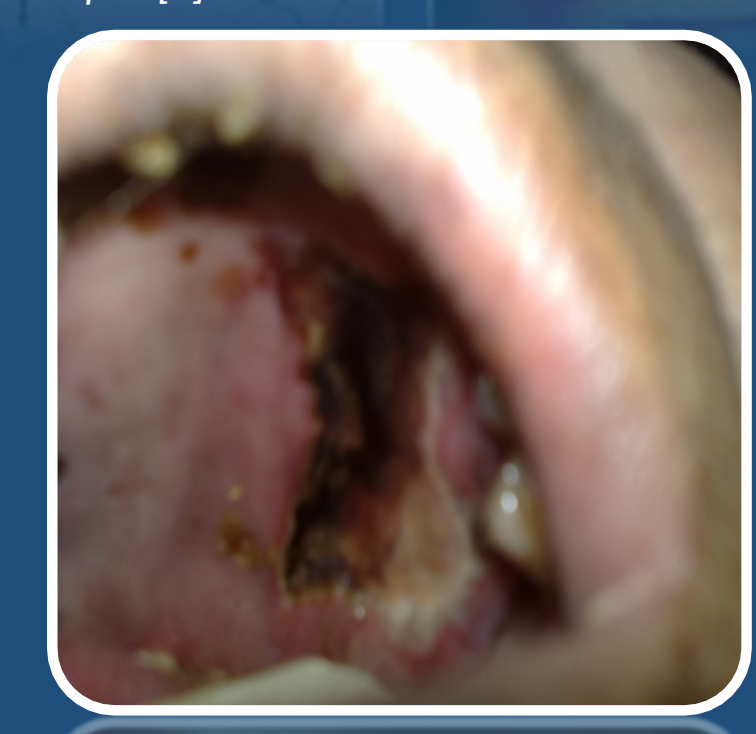

Figure 3: Hard palate ulceration

\section{Method:}

Our single centre case series details the long-term sequelae and disease outcomes of RCM in nine patients between 2000 and 2010 .

- Diagnosis was established through a combination of nasendoscopy, CT imaging of the paranasal sinuses and histopathological assessment of tissue.

\section{Case Series:}

- A total of nine patients were identified; eight of whom were male and one female. The age range of the patients was 45 and 67 years, with an average age of 58.2 years. All patients were known or newly diagnosed diabetics in ketoacidosis at presentation. Presenting symptoms included facial swelling, blurring of vision and blood stained nasal discharge (Table 1).

- Orbital extension occurred in all but one case. This presented as reduced visual acuity, chemosis and proptosis. In advanced, disease ocular movements were limited and complete vision loss occurred. Rhinological symptoms included offensive blood stained rhinorrhoea and pronounced nasal congestion.

- Four cases of intracranial extension were documented: two cases of cerebral abscesses, involving the temporal and frontal lobes, and two cases of extensive skull base osteomyelitis resulting in multiple cranial nerve palsies.

- Hard palate ulceration [Figure 3] and subsequent perforation was observed in six patients. Erythema, ulceration and decreased sensation were all preceding signs.

- Long term prognosis was poor with a mortality rate of $78 \%$. The cause of mortality was related to the sequelae of diabetes mellitus.

\begin{tabular}{|c|c|c|c|c|c|c|}
\hline \multirow{2}{*}{\multicolumn{2}{|c|}{$\begin{array}{c}\text { Age/ } \\
\text { Gender }\end{array}$}} & \multicolumn{4}{|c|}{ Symptomology } & \multirow[t]{2}{*}{ Outcome } \\
\hline & & $\begin{array}{l}\text { Visual/ } \\
\text { Orbital }\end{array}$ & Nasal & Palatal & CNS & \\
\hline 1 & 50/M & Y & $\mathrm{Y}$ & Y & $\mathrm{N}$ & Deceased \\
\hline 2 & $60 / F$ & $\mathrm{Y}$ & $\mathrm{Y}$ & $\mathrm{N}$ & Y & $\begin{array}{l}\text { Long-term } \\
\text { follow-up }\end{array}$ \\
\hline 3 & $45 / M$ & $\mathrm{Y}$ & $\mathrm{Y}$ & $\mathrm{Y}$ & $\mathrm{N}$ & $\begin{array}{l}\text { Long-term } \\
\text { follow-up }\end{array}$ \\
\hline 4 & $65 / M$ & $\mathrm{Y}$ & $\mathrm{Y}$ & $\mathrm{Y}$ & Y & Deceased \\
\hline 5 & $62 / \mathrm{M}$ & $\mathrm{Y}$ & $\mathrm{Y}$ & $\mathrm{N}$ & $\mathrm{N}$ & Deceased \\
\hline 6 & $56 / M$ & $\mathrm{Y}$ & $\mathrm{Y}$ & $\mathrm{N}$ & $\mathrm{N}$ & Deceased \\
\hline 7 & $67 / M$ & $\mathrm{Y}$ & Y & Y & Y & Deceased \\
\hline 8 & $53 / M$ & $\mathrm{~N}$ & Y & $\mathrm{N}$ & Y & Deceased \\
\hline 9 & $66 / M$ & $\mathrm{Y}$ & $\mathrm{Y}$ & $\mathrm{Y}$ & $\mathrm{N}$ & Deceased \\
\hline
\end{tabular}

Table 1: Case Series Summary

\section{Discussion:}

- Rhino-cerebral mucormycosis is a challenging medical condition to treat and requires early diagnosis and a multi-disciplinary team approach involving otolaryngologists, opthalmologists and neurosurgeons.

- In our case series, RCM appeared to mimic acute sinusitis, in keeping with the findings of other studies, which report retro-orbital headaches, facial numbness, fever, hyposmia and nasal congestion as features of the disease.

- In our cohort, the vast majority of patients presented with signs of advanced disease and this late presentation was a key prognosticator of poor outcome.

- RCM has a high mortality in spite of early multimodality imaging, prompt diagnosis, systemic antifungal therapy and fastidious surgical debridement.

\section{References:}

[1] Kontoyiannis DP, Lewis RE. Agents of mucormycosis and Entomophthoramycosis. In: Mandell GL, Bennett GE, Dolin R, eds. Mandell, Douglas and Bennett's
Principles and Practice of Infectious Diseases. 7th ed. Philadelphia, Pa: Churchill Livingstone; 2010:3257-69. Principles and Practice of Infectious Diseases. $7^{\text {th }}$ ed. Philadelphia, Pa: Churchill Livingsto
[2] Szalai G, Fellegi V, Szabo Z, et al. Mucormycosis mimicks sinusitis in a diabetic adult. 